\title{
Novel Approach of Targeted Drug Delivery System and it's Application
}

\author{
Shourabh Rav ${ }^{1}$, Shayam singh Maina ${ }^{1}$, Rachna Malviya ${ }^{1}$, Madan Gopal Kushwah ${ }^{1}$, Mohammad \\ Gayoor khan $^{1 *}$, Umama Yezdani ${ }^{1}$ \\ ${ }^{1 *}$ Truba institute of pharmacy Bhopal M.P, India \\ ${ }^{2}$ MRM college of pharmacy, Hyderabad Telangana, India
}

*Corresponding Author: Mohammad Gayoor khan, Truba institute of pharmacy Bhopal M.P, India. Email:rk981487@gmail.com

\begin{abstract}
The novel drug delivery system is the new and advance method for treating the disease. From the era when the therapeutic response of drug depends mainly upon the interaction of drug molecules with the cell on the cell membrane- related Biological receptors. To achieve this goal the correct amount of drug has to be delivered to the site of action along with simultaneous control of the drug input rate. Generally, after administration of drug located carrier's through only rate undesired bio distribution of drug molecule systemic administration of drug molecules limitations viz, rapid clearance from the systemic circulation either by metabolism inhibited penetrate target tissues or undesired non-specific uptake by sensitive normal tissue or cells.
\end{abstract}

Keywords: microencapsulation, microsphares, dendrimers.

\section{INTRODUCTION}

The novel drug delivery system is the side specific drug delivery system. It is new approach of pharmaceuticals by the using of this technique, in this technique the micron size particle is used for the drug carrier for the drugs the drug is inserted in the polymers and dendrimer and then it injected in the body and give the specific action

New drug delivery system development is largely based on promoting the therapeutic effects of a drug and minimizing its toxic effects by increasing the amount and persistence of a drug in the vicinity of a target cell and reducing the drug exposure of non-target cell. This is still largely based on Paul Ehrlich's magic bullet concept

\section{Benefits and Importance of Targeted Drug Delivery System}

They provide improved or unique clinical benefits, such as

(a) Improvement of patients' compliance

(b) Improved outcomes

(c) Reduction of adverse effects (d) Improvement of patients' acceptance of the treatment

(e) Avoidance of costly interventions such as laboratory services

(f) Allowing patients to receive medication as outpatients, and possibly

(g) A reduction in the overall use of medicinal resources

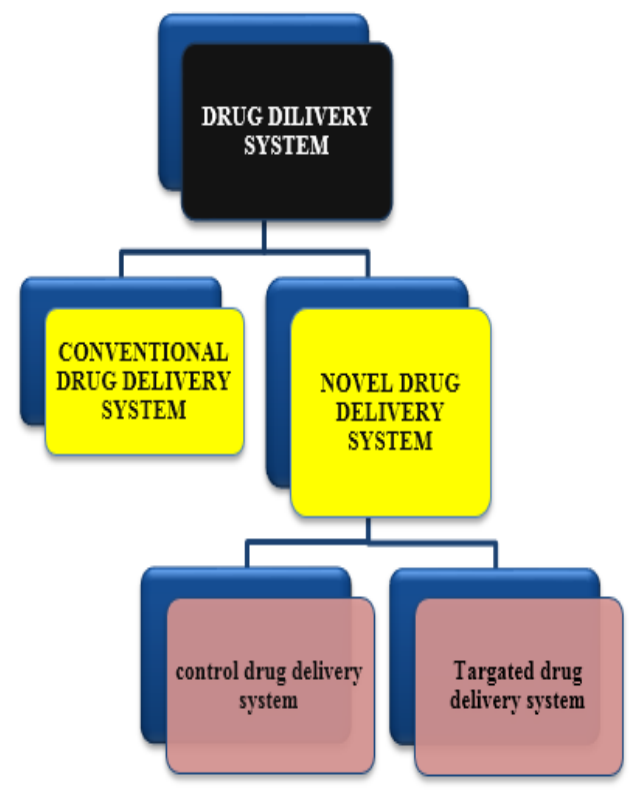




\section{Conventional Drug Delivery System}

The drug delivery system used from ancient time for administration of drugs for the systemic effect and desired therapeutic effects

Eg. Tablets

Capsules

Powders

Granules

\section{Novel Drug Delivery System}

The drug delivery system involves administration of dosage forms to the particular site of action receptor mileu or to target site of specific type of drug delivery

Objectives: site specific

Maintain concentration and biodegradable

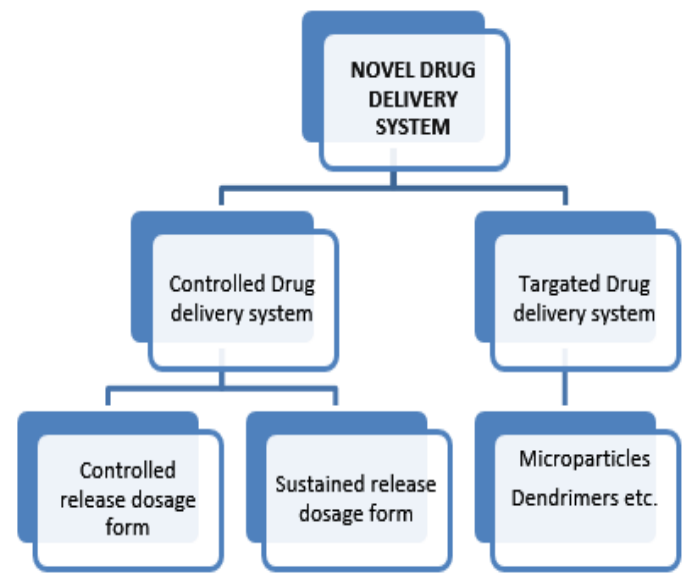

\section{Targated Drug Delivery System (TDDS)}

It is the part of the Novel drug delivery system in this system the microparticals (microsphers and is used microcapsules) dendrimers are used to treat the disease

(1) Microencapsulation: Microencapsulation is a means of applying thin uniform coatings to microparticles of solids dispersion or droplets of liquids

- Microcapsules are small particles that contain an active agent (core material) surrounded by a shell or coating.

- Their diameters generally range from a few microns to a few millimetres.

- Microcapsules can have many different types and structures:

a) simple droplets of liquid core material surrounded by a spherical shell (Microcapsules) b) irregularly-shaped particles containing small particles of solid core material dispersed in a continuous polymer shell matrix (microspheres).

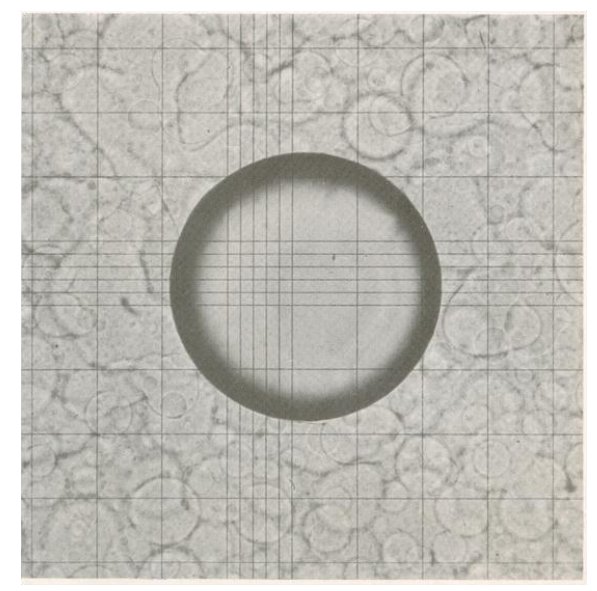

\section{Microencapsulated liquid Application of microencapsulation}

Four important areas of microencapsulation application are:

1. The stabilization of core materials

2. The control of release or availability of core materials

3. Separation of chemically reactive ingredients within a tablet or powder mixture.

4. Taste-masking.

*Dendrimers: Dendrimers are a new class of polymeric materials. They are highly branched, mono-disperse macromolecules. The structure of these materials has a great impact on their physical and chemical properties. As a result of their unique behaviour dendrimers are suitable for a wide range of biomedical and industrial applications.

- Dendrimers ability to succeed as a drug delivery system depends upon the ability to readily structure control their six "critical nanoscale design parameters "

- $\quad$ size

- shape

- surface chemistry

- flexibility/

- rigidity

- architecture

- elemental composition 


\section{Dendrimer: Precise Polymeric Nanostructures}

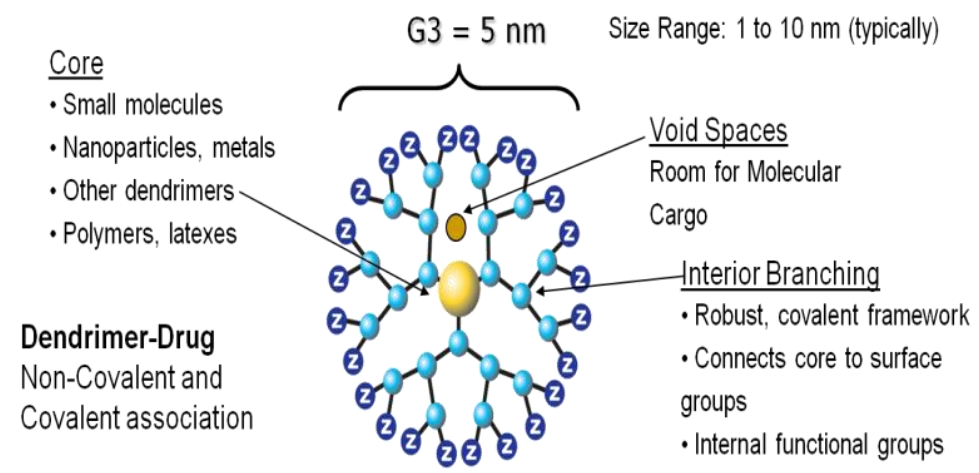

- Dendrimer is an Architecture

- Chemical composition may differ Surface Groups

- Hydrophilic: Cationic, Anionic, \& Neutral

- Hydrophobic: aliphatic \& aromatic

- Combinations of surface groups

- Number doubles or triples per generation

\section{ACKNOWLEDGMENT}

First of all I would like to Thank my Co- Author's Mr. Md.Gayoor khan, Ms. Umama Yezdani (Department of clinical and Pharmacy Practice) MRM college of Pharmacy Hyderabad, India , Mr. Madan Gopal, Shayam, Rachna Malviya. The authors are thankful to Dr. Rajesh Singh Pawar, PhD. Principal Truba Institute of Pharmacy for ceaseless encouragement during the study and Prof. Vinod Dhote sir for all time guidance and encouragement.

\section{REFERENCES}

[1] Gayoor Khan, Umama Yezdani, Rohit Verma, Raqshan Jabeen, Pradeep Sintha.Detection of Phlebovirus by using qualitative Real time (RT) - PCR and application of silver nanoparticles to control it. World J Pharm Pharm Sci., 2018; 7(11): 936-52.

[2] Mohd. Gayoor Khan. The Novel Drug Delivery System. World J Pharm Pharm Sci., 2017; 6(7): 477-487.

[3] Unama Yezdani, Mohd. Gayoor Khan, Fazal Khan, Arvind Verma, Nilesh Kushwah, Rohit Verma. The Drug Targeting in Alzheimer's or Applications \& it's Hazards. World J Pharm Pharm Sci., 2017; 7(11): 1532-1549.

[4] Dr. H.S Chandel., Sharad P.Panday, Arvind Dangi, Ashish chaurasia, Mohd.Gayoor khan. Development of Targeted Drug delivery. International Journal of research methodology Ijrm. Human., 2017; 1(2): 30-34.

[5] Kushwah Nilesh, Yezdani Umama, Mohammad Gayoor khan, Manish kushwah, Kumar Ayush. The Fundamental of Novel Drug Delivery System; Methodology, Role of Nanotechnology;
Nanoparticles in Pharmaceutical Research. International Journal of Emerging Technologies and Innovative Research (www.jetir.org), ISSN:2349-5162, June-2019; 6(6): 140-146. DOI: http://doi.one/10.1729/Journal.21510.

[6] Mohd. Gayoor Khan, Nilesh Kushwaha, Fazal Khan, Vipul Patel. Microencapsulation. International Journal of research methodology Ijrm. Human., 2017; 1(2): 35-42.

[7] Umama Yezdani, Mohd. Gayoor Khan, Nilesh Kushwah, Arvind Verma, Fazal Khan. Application of Nanotechnology in Diagnosis and treatment of various disease and it's future advances in medicine. World J Pharm Pharm Sci., 2018; 7(11): 1611-1633.

[8] Yezdani Umama, Venkatajah G, Rav Shourabh, Roshan Kumar, Arvind Verma, Ayush Kumar, Md. Khan Gayoor. Topic-The scenario of pharmaceuticals and development of microwave assisted extraction technique. World J Pharm Pharm Sci., 2019; 8(7): 1260-1271.

[9] Mohd. Gayoor khan. Radiopharmaceuticals Drug interactions. IJCRP, 2017; 1(5):40-47.

[10] Dr. Umama Yezdani, Rohit verma, Mr. Ajay Kumar, Krishna Kumar Pandey, Mohd.Gayoor khan. The fundamental \& Development role of epidural steroid injection in management of herniated intervertebral disc with Radiculopathy. IJCRP,2017; 1(5): 40-47.

[11] Khan MG, Gauttam V, Chandel HS, Ali A, Tariq K. Development of Microencapsulation: A Review of Literature. Int J Sci Stud, 2016; 5(4): 264-268.

[12] Mohd.Gayoor Khan. The Novel Drug Delivery System. World J Pharm Pharm Sci. 2017;6(7) :477-487. 
[13] Mohammad Gayoor Khan Umama Yezdani, Shivam Choudghal, Sana Rahman, Mayur Sadar, Ayush Kumar.A Brief Study on Motor Neuron Disease; and its Treatment Includes Drug Delivery System; Future Aspects on Neurological Science" IOSR Journal of Pharmacy and Biological Sciences (IOSRJPBS) 14.4 (2019): 52-56.
[14] Ansel's Pharmaceutical Dosage Forms and Drug Delivery Systems EIGHTH EDITION Loyd V Allen,je. Nicholas G.popovich and Howard C.Ansel pulished by Wolters kluwer (india) Pvt.Ltd.,New Dehli

Citation: Shourabh Rav, et al, Novel Approach of Targeted Drug Delivery System and it's Application. ARC Journal of Public Health and Community Medicine.2019; 4(4):1-4. DOI: dx.doi.org/10.20431/2456-0596 .0404001 .

Copyright: (C) 2019 Authors. This is an open-access article distributed under the terms of the Creative Commons Attribution License, which permits unrestricted use, distribution, and reproduction in any medium, provided the original author and source are credited. 